\title{
SUPERIOR PROTECTION IN ORTHOTOPIC RAT LUNG TRANSPLANTATION WITH CYCLIC ADENOSINE MONOPHOSPHATE AND NITROGLYCERIN-CONTAINING PRESERVATION SOLUTION
}

Koichi Kayano, MD, PhD

Koichi Toda, MD

Yoshifumi Naka, MD, PhD

Kenji Okada, MD, PhD

Mehmet C. Oz, MD

David J. Pinsky, MD
Background: Primary lung graft failure is common, and current lung preservation strategies are suboptimal. Because the decline in lung levels of cyclic adenosine monophosphate and cyclic guanosine monophosphate during preservation could enhance adhesiveness of endothelial cells for leukocytes as well as increase vascular permeability and vasoconstriction, we hypothesized that buttressing these levels by means of a preservation solution would significantly improve lung preservation. Methods: An orthotopic rat left lung transplantation model was used. Lungs were harvested from male Lewis rats and preserved for 6 hours at $4^{\circ} \mathrm{C}$ with (1) Euro-Collins solution ( $\left.n=8\right)$; (2) University of Wisconsin solution ( $n=8$ ); (3) low-potassium dextran glucose solution ( $n=8)$; (4) Columbia University solution $(n=8)$, which contains a cyclic adenosine monophosphate analog (dibutyryl cyclic adenosine monophosphate) and a nitric oxide donor (nitroglycerin) to buttress cyclic guanosine monophosphate levels; or (5) Columbia University solution without cyclic adenosine monophosphate or nitroglycerin $(\mathrm{n}=8)$. $\mathrm{PaO}_{2}$, pulmonary vascular resistance, and recipient survival were evaluated 30 minutes after left lung transplantation and removal of the nontransplanted right lung from the pulmonary circulation. Results: Among all groups studied, grafts stored with Columbia University solution demonstrated the highest $\mathrm{PaO}_{2}(355 \pm 25 \mathrm{~mm} \mathrm{Hg}$ for Columbia University solution versus $95 \pm 22 \mathrm{~mm}$ Hg for Euro-Collins solution, $P<.01,172 \pm 55$ $\mathrm{mm} \mathrm{Hg}$ for University of Wisconsin solution, $P<.05,76 \pm 15 \mathrm{~mm} \mathrm{Hg}$ for low-potassium dextran glucose solution, $P<.01$, and $82 \pm 25 \mathrm{~mm} \mathrm{Hg}$ for Columbia University solution without cyclic adenosine monophosphate or nitroglycerin, $P<.01$ ) and the lowest pulmonary vascular resistances $\left(1 \pm 0.2 \mathrm{~mm} \mathrm{Hg} \cdot \mathrm{mL}^{-1} \cdot \mathrm{min}^{-1}\right.$ for Columbia University solution versus $12 \pm 4 \mathrm{~mm} \mathrm{Hg} \cdot \mathrm{mL}^{-1} \cdot \mathrm{min}^{-1}$ for Euro-Collins solution, $P<.01,9 \pm 2 \mathrm{~mm}$ $\mathrm{Hg} \cdot \mathrm{mL}^{-1} \cdot \mathrm{min}^{-1}$ for University of Wisconsin solution, $14 \pm 6 \mathrm{~mm} \mathrm{Hg} \cdot$ $\mathrm{mL}^{-1} \cdot \mathrm{min}^{-1}$ for low-potassium dextran glucose solution, $P<.01$, and 8 $\pm 2 \mathrm{~mm} \mathrm{Hg} \cdot \mathrm{mL}^{-1} \cdot \mathrm{min}^{-1}$ for Columbia University solution without cyclic adenosine monophosphate and nitroglycerin). These functional and hemodynamic improvements provided by Columbia University solution were accompanied by decreased graft leukostasis and decreased recipient tumor necrosis factor $\alpha$ and interleukin $1 \alpha$ levels compared with the other groups. In toto, these improvements translated into superior survival among recipients of Columbia University solution-preserved grafts $\mathbf{1 0 0 \%}$ for Columbia University solution, $\mathbf{3 7 \%}$ for
From the College of Physicians and Surgeons of Columbia University, New York.

Supported in part by the United States Public Health Service (grants RO1 HL55397 and RO1 HL59488). Dr Pinsky is a ClinicianScientist of the American Heart Association, Dallas, Tex.

Presented in part at the Seventieth Scientific Sessions of the American Heart Association, Orlando, Florida, November 9-12, 1997.

Received for publication Sept 28, 1998; revisions requested Dec 15,
1998; revisions received March 5, 1999; accepted for publication March 8, 1999.

Address for reprints: David J. Pinsky, MD, Columbia University, College of Physicians and Surgeons, PH 10 Stem, 630 W, 168th St, New York, NY 10032.

J Thorac Cardiovasc Surg 1999;118:135-44

Copyright (C) 1999 by Mosby, Inc.

$0022-5223 / 99 \$ 8.00+0 \quad \mathbf{1 2 / 1 / 9 8 4 2 4}$ 
Euro-Collins solution, $P<.01,50 \%$ for University of Wisconsin solution, $P<.05,50 \%$ for low-potassium dextran glucose solution, $P<.05$, and $13 \%$ for Columbia University solution without cyclic adenosine monophosphate and nitroglycerin, $P<.01)$. Conclusion: Nitroglycerin and cyclic adenosine monophosphate confer beneficial vascular effects that make Columbia University solution a superior lung preservation solution in a stringent rat lung transplantation model. ( $J$ Thorac Cardiovasc Surg 1999;118:135-44)

$T^{\mathrm{h}}$ he transplantation of solid organs is becoming an increasingly important therapeutic option for patients with end-stage disease of a single organ system. Among the solid organs that are transplanted, the experience with lung transplantation has arguably been the worst, with only about $70 \%$ of patients surviving for 1 year. ${ }^{1}$ One of the major impediments in lung transplantation is the exquisite vulnerability of the lungs to harvest, storage, and transplantation procedures, with a resulting incidence of primary graft failure as high as approximately $15 \%$ within 30 days after transplantation. ${ }^{1,2}$ New mechanistic insights into reasons underlying primary lung graft failure, which could lead to means for its prevention, would come as a welcome relief to the transplantation community.

Designs of lung preservation solutions in current clinical use have centered on maintaining physicochemical properties of the ex vivo organ. We hypothesized that although tonicity, osmolality, and $\mathrm{pH}$ may be important properties of an optimal preservation solution, strategies to maintain endothelial homeostatic properties are also of critical importance. Our recent work has focused on the importance of maintaining endothelial function within transplanted organs as critical to successful preservation, ${ }^{3-9}$ especially of lungs because the lung has a delicate alveolar and capillary network. From data obtained through in vitro studies of hypoxic and reoxygenated endothelial cells to serve as a paradigm for the ischemic and reperfused vascular milieu of lung transplantation, we designed a preservation solution ${ }^{10}$ that was based on the following considerations. Hypoxia and reoxygenation significantly increase permeability of endothelial monolayers, ${ }^{11}$ enhance leukocyte-endothelial cell interactions, ${ }^{12,13}$ and depress nitric oxide and cyclic adenosine monophosphate (cAMP) levels (the former as a result of quenching by superoxide generated during reoxygenation and the latter as a result of reduced adenylate cyclase activity). ${ }^{14}$ The reperfusion period after organ transplantation has been characterized as a time during which nitric oxide levels plummet, with an attendant reduction in tissue cyclic guanosine monophosphate
(cGMP) levels (as a result of reduced stimulation of soluble guanylate cyclase by bioavailable nitric oxide) and reduced cAMP levels, perhaps as the result of a combined reduction in endothelial adenylate cyclase activity and increase in types III and IV phosphodiesterase activity in vascular smooth muscle cells.

The deficiencies in these 2 pathways, nitric oxide-cGMP and cAMP, are likely to be important reasons underlying primary graft failure. During organ preservation and reperfusion both cAMP and nitric oxide play central roles in maintaining pulmonary vascular homeostasis. cAMP helps to maintain control of endothelial barrier function, ${ }^{14,15}$ endothelial cellleukocyte interactions, ${ }^{16,17}$ and vascular smooth muscle tone. ${ }^{18}$ Nitric oxide, an important messenger that can act in an autocrine or paracrine manner, also influences vascular permeability, ${ }_{19}^{19}$ leukocyte-vessel wall interactions,${ }^{20}$ endothelial thrombogenicity, ${ }^{21}$ and vasomotor tone by stimulating soluble guanylate cyclase to increase cGMP. We hypothesized that supplementing deficient cAMP and nitric oxide-cGMP pathways might improve lung preservation for transplantation and therefore designed a new storage solution that could replenish these intercellular and intracellular messengers. To investigate the efficacy of the new solution, we used a rat lung transplantation model to compare it with other lung preservation solutions in common clinical or experimental use.

\section{Methods}

Rat orthotopic left lung transplantation model. Inbred male Lewis rats (250-300 g) were used for all experiments according to a protocol approved by the Institutional Animal Care and Use Committee at Columbia University, in accordance with guidelines of the American Association for the Accreditation of Laboratory Animal Care. Donor rats were given 500 units heparin intravenously and the pulmonary artery was flushed with a $30-\mathrm{mL}$ volume of $4^{\circ} \mathrm{C}$ preservation solution at a constant pressure of $20 \mathrm{~mm} \mathrm{Hg}(1 \mathrm{~mm} \mathrm{Hg}=133$ $\mathrm{Pa}$ ), with egress of preservation solution from the left atrium during the flushing procedure facilitated by a large slit made in the left atrium before flushing. The time required to infuse the $30-\mathrm{mL}$ volume of preservation solution under constant 
Table I. Compositions of preservation solutions

\begin{tabular}{|c|c|c|c|c|}
\hline & $\begin{array}{l}\text { Euro-Collins } \\
\text { solution }\end{array}$ & $\begin{array}{l}\text { University of } \\
\text { Wisconsin } \\
\text { solution }\end{array}$ & $\begin{array}{l}\text { Low-potassium } \\
\text { dextran glucose } \\
\text { solution }\end{array}$ & $\begin{array}{c}\text { Columbia } \\
\text { University } \\
\text { solution }\end{array}$ \\
\hline \multicolumn{5}{|l|}{ Base preservation solution } \\
\hline Potassium (mmol/L) & 115 & 125 & 4 & 120 \\
\hline Sodium $(\mathrm{mmol} / \mathrm{L})$ & 10 & 30 & 165 & - \\
\hline Magnesium (mmol/L) & 8 & 5 & 2 & 5 \\
\hline Chloride $(\mathrm{mmol} / \mathrm{L})$ & - & - & 101 & - \\
\hline Bicarbonate $(\mathrm{mmol} / \mathrm{L})$ & 10 & - & - & - \\
\hline Phosphate $(\mathrm{mmol} / \mathrm{L})$ & 100 & 25 & 34 & 25 \\
\hline Sulfate $(\mathrm{mmol} / \mathrm{L})$ & 8 & 5 & 2 & 5 \\
\hline Gluconate $(\mathrm{mmol} / \mathrm{L})$ & - & - & - & 95 \\
\hline Lactobionate $(\mathrm{mmol} / \mathrm{L})$ & - & 100 & - & - \\
\hline Colloid $(\mathrm{g} / \mathrm{L})$ & - & Hydroxyethyl starch, 50 & Dextran-40, 20 & Dextran 50 \\
\hline Glucose (mmol/L) & 120 & - & 56 & 67 \\
\hline \multicolumn{5}{|l|}{ Additives } \\
\hline Adenosine (mmol/L) & - & 5 & - & 5 \\
\hline Allopurinol (mmol/L) & - & 1 & - & - \\
\hline $\mathrm{db}-\mathrm{cAMP}(\mathrm{mmol} / \mathrm{L})$ & - & - & - & 2 \\
\hline Nitroglycerin $(\mathrm{mg} / \mathrm{mL})$ & - & - & - & 0.1 \\
\hline Butylated hydroxyanisole $(\mu \mathrm{mol} / \mathrm{L})$ & - & - & - & 50 \\
\hline Butylated hydroxytoluene $(\mu \mathrm{mol} / \mathrm{L})$ & - & - & - & 50 \\
\hline$N$-Acetylcysteine $(\mathrm{mmol} / \mathrm{L})$ & - & - & - & 0.5 \\
\hline Heparin $(\mathrm{U} / \mathrm{mL})$ & - & - & - & 10 \\
\hline Verapamil $(\mu \mathrm{mol} / \mathrm{L})$ & - & - & - & 10 \\
\hline \multicolumn{5}{|l|}{ Physical composition } \\
\hline $\mathrm{pH}$ & 7.4 & 7.4 & 7.4 & 7.6 \\
\hline Osmolality (mOsm/L) & 452 & 327 & 335 & 325 \\
\hline
\end{tabular}

pressure was recorded as the "flushing time," which served as an index of pulmonary vascular resistance (PVR) during lung harvest. The left lung was then excised, a cuff was placed on each vascular and the bronchial stump, and the lung was submerged for 6 hours at $4^{\circ} \mathrm{C}$ in a preservation solution of the same composition as that used for flushing. Four different preservation solutions were used; compositions are listed in Table I. Columbia University solution, which contains a cAMP analog, dibutyryl cAMP (db-cAMP) and nitroglycerin, was prepared as described in our previous article. ${ }^{10}$ As an additional control a version of Columbia University solution was also prepared without either a cAMP analog or nitroglycerin. Euro-Collins solution was obtained from Baxter Healthcare (Baxter Healthcare Corporation, Deerfield, Ill) and modified by adding $10 \mathrm{~mL} 10 \%$ magnesium sulfate and $50 \mathrm{~mL}$ $50 \%$ glucose solution per $940 \mathrm{~mL}$. University of Wisconsin solution was obtained from Du Pont Pharmaceuticals (E. I. du Pont de Nemours and Company, Wilmington, Del). Lowpotassium dextran glucose solution was prepared as described in a previous report. ${ }^{22}$

Rats matched for sex, strain, and size were anesthetized, intubated, and ventilated with $100 \%$ oxygen by means of a rodent ventilator (Harvard Apparatus, Inc, Holliston, Mass). Orthotopic left lung transplantation was performed through a left thoracotomy by means of a rapid cuff technique for all 3 anastomoses, with warm ischemic times maintained at less than 5 minutes. The hilar crossclamp was released, reestab- lishing blood flow and ventilation to the transplanted lung. The right lung was then functionally removed from the recipient after reperfusion of the left lung and placement of the flow and pressure measuring devices in the main pulmonary artery (2F Millar catheter; Millar Instruments, Inc, Houston, Tex) and around the main pulmonary artery (2-mm Doppler Flow Probe; Transonic Systems, Inc, Ithaca, NY). This model was adopted on the basis of previously published procedures. ${ }^{3}$

Measurement of lung graft function. On-line hemodynamic monitoring was accomplished with MacLab (McLab Instruments, Boston, Mass) and a Macintosh IIci computer (Apple Computer, Inc, Cupertino, Calif). Measured hemodynamic parameters included pulmonary arterial pressure (in millimeters of mercury) and pulmonary arterial flow (in milliliters per minute). The $\mathrm{PaO}_{2}$ (in millimeters of mercury) was measured during inspiration of $100 \%$ oxygen with a model ABL-2 gas analyzer (Radiometer Medical A/S, Brønshøj, Denmark). PVR, expressed as millimeters of mercury per milliliter per minute, was calculated as follows: $\mathrm{PVR}=($ mean pulmonary arterial pressure - left atrial pressure)/mean pulmonary arterial flow. After baseline measurements the native right pulmonary artery was ligated and serial hemodynamic measurements were taken every 5 minutes until 30 minutes or recipient death. In addition to hemodynamic measurements, arterial blood for gas analysis was sampled at baseline and at either 30 minutes or the final time at which the recipient was alive. 


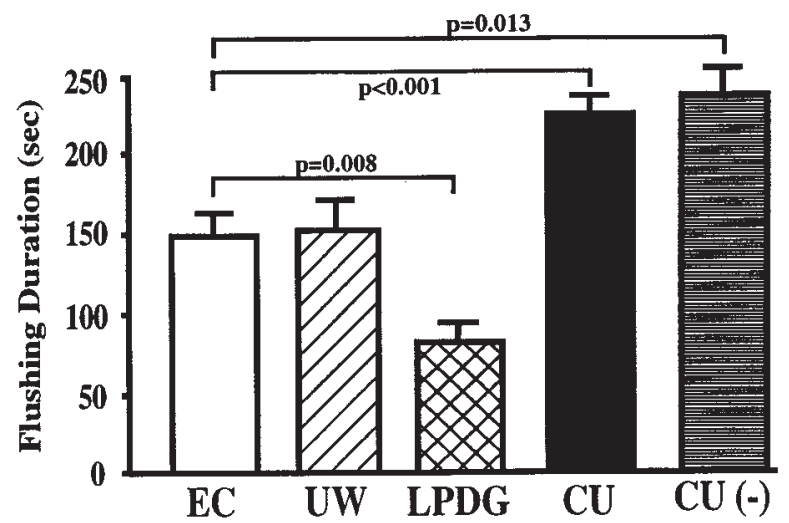

Fig 1. Effect of preservation solution composition on pulmonary vascular resistance during lung harvest. After anesthesia, left atrium was vented and pulmonary artery was flushed with $30-\mathrm{mL}$ volume of indicated preservation solution $\left(4^{\circ} \mathrm{C}\right)$ at constant infusion pressure of $20 \mathrm{~mm} \mathrm{Hg}$. Flushing duration (in seconds) was measured as index of harvest pulmonary vascular resistance. $E C$, Euro-Collins solution; $U W$, University of Wisconsin solution; $L P D G$, lowpotassium dextran glucose solution; $C U$, Columbia University solution; $C U(-)$, Columbia University solution without db-cAMP and nitroglycerin. Compositions of these solutions are described in Table I. For each group $\mathrm{N}=8$. Boxes represent means; error bars indicate SEM.

Myeloperoxidase assay. Thirty minutes after ligation of the native right pulmonary artery, or at the time of recipient death, the transplanted lung was removed, rinsed briskly in physiologic saline solution, and snap frozen in liquid nitrogen until the time of myeloperoxidase assay, which was performed as described previously. ${ }^{6}$ Change in absorbance at $460 \mathrm{~nm}$ was measured across 30 seconds (increase in optical density was linear during this time interval). Myeloperoxidase activity was expressed as change in absorbance at 460 $\mathrm{nm}$ per minute.

Measurement of tumor necrosis factor $\alpha$ and interleukin $1 \alpha$. A heparinized blood sample was taken from the recipient 30 minutes after ligation of the right pulmonary artery, or at the time of recipient death, and was centrifuged for 10 minutes at $14,000 \mathrm{rpm}$. The supernatant was recovered and frozen at $-80^{\circ} \mathrm{C}$ until the time of assay. Assays for tumor necrosis factor $\alpha$ (TNF- $\alpha$ ) and interleukin $1 \alpha$ (IL- $1 \alpha)$ were performed with enzyme-linked immunosorbent assays for rat TNF- $\alpha$ and IL- $1 \alpha$ according to procedures suggested by the manufacturer (Genzyme Corporation, Cambridge, Mass). Assays were performed in duplicate, with standards run each time the assay was performed. The lower limits for detection in these assays were $10 \mathrm{pg} / \mathrm{mL}$ for TNF- $\alpha$ and $15 \mathrm{pg} / \mathrm{mL}$ for IL- $1 \alpha$.

Statistics. Comparisons between groups were performed with the Mann-Whitney $U$ test. Animal survival data were analyzed by contingency analysis with the $\chi^{2}$ statistic. Values are expressed as mean \pm SEM.

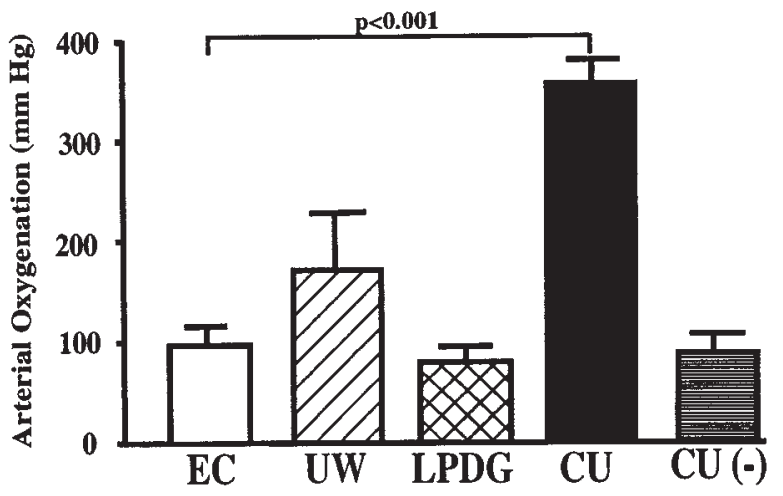

Fig 2. Effect of preservation solution composition on arterial oxygenation after lung transplantation. Donor lungs were harvested and preserved with indicated solution for 6 hours at $4^{\circ} \mathrm{C}$ and transplanted orthotopically into strain-matched recipient. After transplantation native right pulmonary artery was ligated, and 30 minutes later (or just before recipient death), $200 \mu \mathrm{L}$ left ventricular blood was obtained to determine arterial oxygenation. EC, Euro-Collins solution; $U W$, University of Wisconsin solution; $L P D G$, low-potassium dextran glucose solution; $C U$, Columbia University solution; $C U(-)$, Columbia University solution without db-cAMP and nitroglycerin. For each group $\mathrm{N}=8$. Boxes represent means; error bars indicate SEM.

\section{Results}

For initial experiments we measured the amount of time required to flush in a constant volume of preservation solution under constant pressure. This "flushing duration" should reflect both the vasoconstriction that occurs during lung harvest and the viscosity of the infusate at the hypothermic temperatures used. Five different preservation solutions were compared: EuroCollins solution, University of Wisconsin solution, lowpotassium dextran glucose solution, Columbia University solution, and Columbia University solution without db-cAMP and nitroglycerin. All solutions tested that contained "intracellular" levels of potassium (range 115-125 mmol/L for Euro-Collins solution, University of Wisconsin solution, Columbia University solution, and Columbia University solution without db-cAMP and nitroglycerin) were associated with vasoconstriction during harvest relative to that seen with low-potassium dextran glucose solution (Fig 1). Of the solutions tested, Columbia University solution required the longest time to infuse, suggesting that vascular resistance during the initial pulmonary flush with Columbia University solution is higher than that with other solutions (Fig 1), even though Columbia University solution contains the vasodilators nitroglycerin and db-cAMP. 


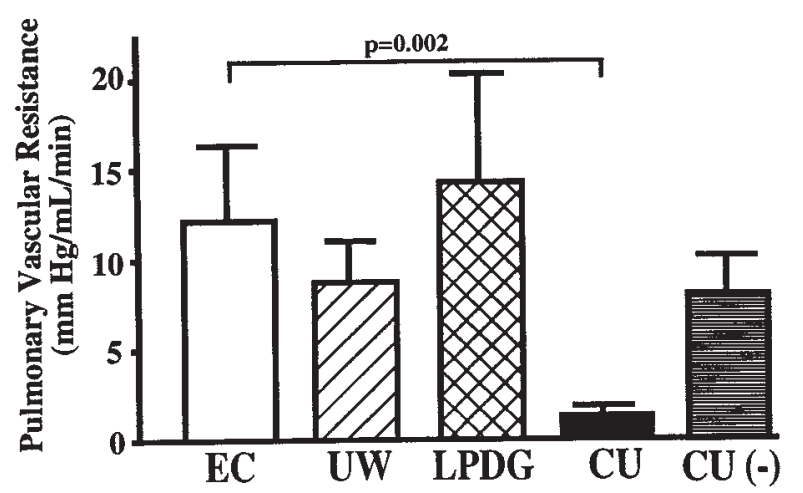

Fig 3. Effect of preservation solution composition on PVR after lung transplantation. Experiments were performed as described in legend to Fig 2. PVR was calculated as described in text. $E C$, Euro-Collins solution; $U W$, University of Wisconsin solution; $L P D G$, low-potassium dextran glucose solution; $C U$, Columbia University solution; $C U(-)$, Columbia University solution without db-cAMP and nitroglycerin. For each group $\mathrm{N}=8$. Boxes represent means; error bars indicate SEM.

Because in previous work we showed that other properties of lung preservation solutions, especially those that preserve endothelial homeostasis, are of greater importance than their effects to reduce harvest pulmonary vascular resistance, harvested lungs were transplanted to determine the relative preservative effects of these 4 preservation solutions. For these experiments, after the initial flush lungs were immersed for 6 hours at $4^{\circ} \mathrm{C}$ in a preservation solution of identical composition to that used for flushing, after which they were transplanted in an extremely stringent orthotopic rat left lung transplantation model that we have previously reported. ${ }^{23}$ Immediately after the vascular and bronchial anastomoses were completed the nontransplanted right lung was effectively removed from the pulmonary circulation by ligation of the right pulmonary artery. In this way the lung graft recipient was forced to survive solely on the basis of the function of the transplanted lung. The 5 different preservation solutions (Euro-Collins solution, University of Wisconsin solution, low-potassium dextran glucose solution, Columbia University solution, and Columbia University solution without db-cAMP or nitroglycerin) differed markedly in ability to preserve lungs. In groups that received lungs preserved with Euro-Collins solution, University of Wisconsin solution, low-potassium dextran glucose solution, and Columbia University solution without db-cAMP or nitroglycerin, arterial oxygenation was poor after transplantation $\left(\mathrm{PaO}_{2} 95 \pm 22 \mathrm{~mm} \mathrm{Hg}, 172 \pm 55 \mathrm{~mm} \mathrm{Hg}, 76 \pm 15 \mathrm{~mm}\right.$

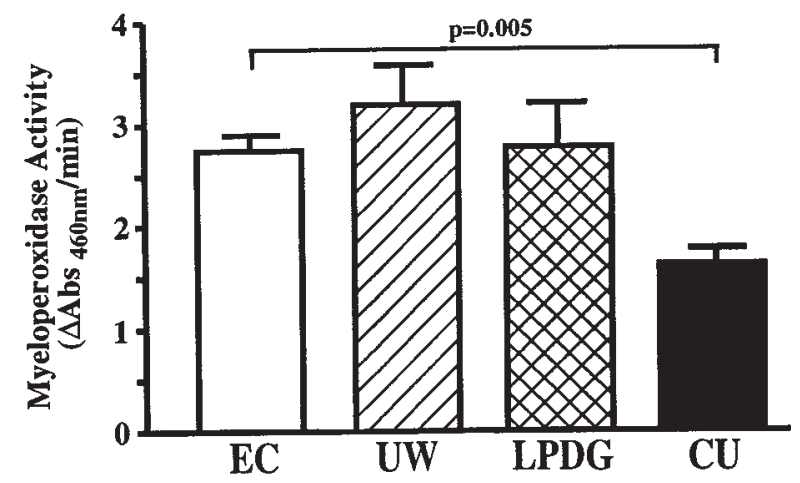

Fig 4. Effect of preservation solution composition on graft neutrophil accumulation after lung transplantation. Experiments were performed as described in legend to Fig 2. Lungs were removed at 30 minutes after right pulmonary arterial ligation (or at recipient death if it preceded 30-minute time point), snap frozen in liquid nitrogen, and kept at $-80^{\circ} \mathrm{C}$ until time of assay. Myeloperoxidase activity, as change in absorbance $(\triangle A b s)$ at $460 \mathrm{~nm}$ per minute, was used to quantify neutrophil accumulation. EC, Euro-Collins solution; $U W$, University of Wisconsin solution; $L P D G$, low-potassium dextran glucose solution; $C U$, Columbia University solution; $C U(-)$, Columbia University solution without db-cAMP and nitroglycerin. For each group $\mathrm{N}=8$. Boxes represent means; error bars indicate SEM.

$\mathrm{Hg}$, and $82 \pm 25 \mathrm{~mm} \mathrm{Hg}$, respectively; Fig 2). In contrast, arterial oxygenation after transplantation of lungs preserved in Columbia University solution was significantly greater $\left(\mathrm{PaO}_{2} 355 \pm 25 \mathrm{~mm} \mathrm{Hg}, P<0.05\right.$ versus all other groups; Fig 2).

Another critical reason for early recipient death stems from flow limitation through the pulmonary vascular bed. To evaluate this possibility, pulmonary vascular resistance was determined after lung transplantation through simultaneous measurements of pulmonary arterial flow and pressure. Animals that received lungs preserved with Euro-Collins solution, University of Wisconsin solution, low-potassium dextran glucose solution, and Columbia University solution without $\mathrm{db}$ cAMP or nitroglycerin demonstrated significant limitation of flow to the graft $(6.2 \pm 2.5 \mathrm{~mL} / \mathrm{min}, 5.1 \pm 2.4$ $\mathrm{mL} / \mathrm{min}, 7.2 \pm 3.0 \mathrm{~mL} / \mathrm{min}$, and $4.1 \pm 1.7 \mathrm{~mL} / \mathrm{min}$, respectively) despite relative preservation of pulmonary arterial pressures. This resulted in markedly elevated PVR after transplantation (Fig 3). In sharp contrast, grafts that had been preserved with Columbia University solution and transplanted in an identical manner demonstrated relatively well-preserved pulmonary arterial pressure and flow $(20.7 \pm 1.0 \mathrm{~mL} / \mathrm{min}$, $P<.01$ versus all other groups), resulting in low pul- 


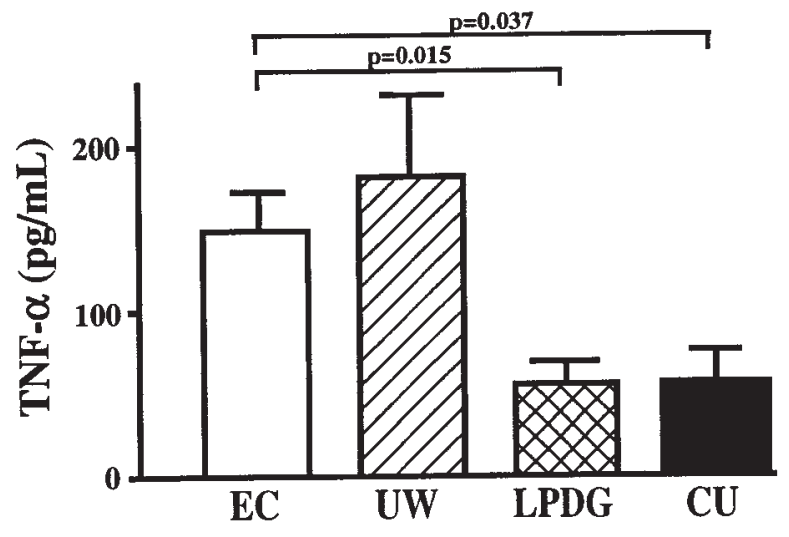

Fig 5. Effect of preservation solution composition on recipient TNF- $\alpha$ levels after lung transplantation. Experiments were performed as described in legend to Fig 2. Heparinized blood samples were taken from left ventricle at 30 minutes after right pulmonary arterial ligation (or at recipient death if it preceded 30-minute time point). After centrifugation to remove cellular elements, plasma was assayed for TNF- $\alpha$ by enzyme-linked immunosorbent assay. $E C$, Euro-Collins solution; $U W$, University of Wisconsin solution; $L P D G$, lowpotassium dextran glucose solution; $C U$, Columbia University solution; $C U(-)$, Columbia University solution without db-cAMP and nitroglycerin. For each group $\mathrm{N}=8$ blood samples assayed in duplicate. Boxes represent means; error bars indicate SEM.

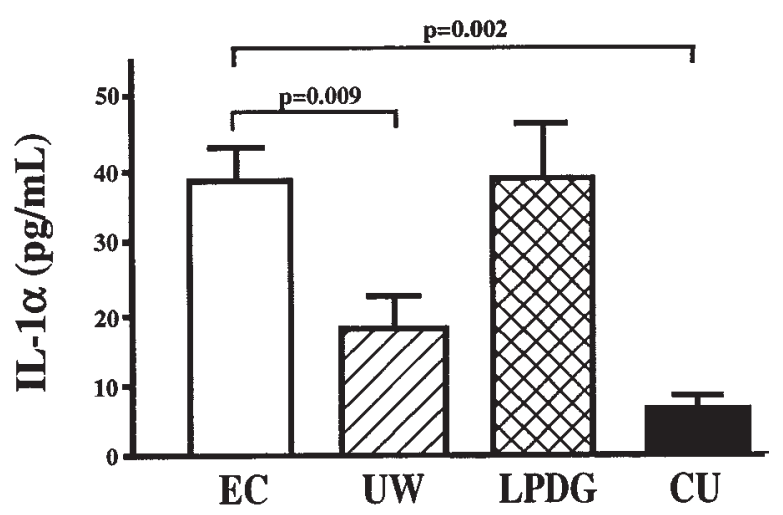

Fig 6. Effect of preservation solution composition on recipient IL- $1 \alpha$ levels after lung transplantation. Experiments were performed as described in legend to Fig 2. Heparinized blood samples were taken from left ventricle at 30 minutes after right pulmonary arterial ligation (or at recipient death if it preceded 30-minute time point). After centrifugation to remove cellular elements, plasma was assayed for IL- $1 \alpha$ by enzyme-linked immunosorbent assay. For each group $\mathrm{N}=8$ blood samples assayed in duplicate. EC, Euro-Collins solution; $U W$, University of Wisconsin solution; $L P D G$, lowpotassium dextran glucose solution; $C U$, Columbia University solution; $C U(-)$, Columbia University solution without db-cAMP and nitroglycerin. Boxes represent means; error bars indicate SEM.

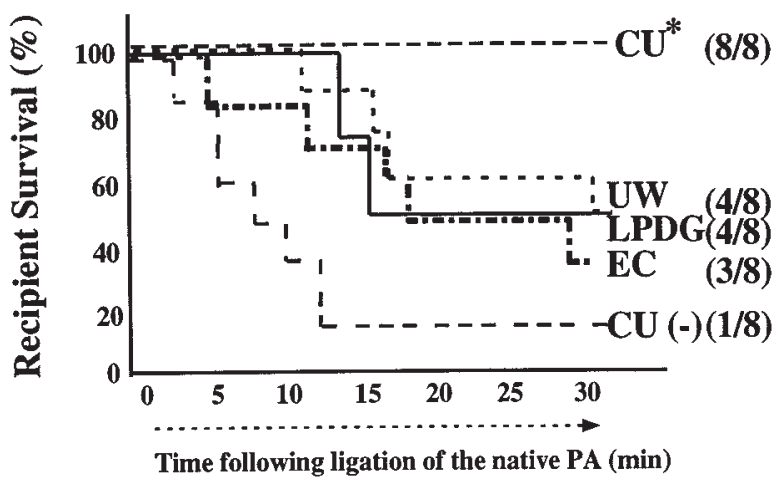

Fig 7. Effect of preservation solution composition on recipient survival after lung transplantation. Experiments were performed as described in legend to Fig 2; after ligation of contralateral (right) pulmonary artery $(P A)$, time was recorded until recipient death or until previously specified killing time at 30 minutes. Death was defined a priori as a pulmonary arterial flow of zero. Number of surviving recipients (numerator) and total number of transplantation experiments (denominator) are shown for each preservation solution. EC, Euro-Collins solution; $U W$, University of Wisconsin solution; $L P D G$, low-potassium dextran glucose solution; $C U$, Columbia University solution; $C U(-)$, Columbia University solution without db-cAMP and nitroglycerin. Asterisk indicates $P=.021$ versus University of Wisconsin solution and low-potassium dextran glucose solution, $P=.007$ versus Euro-Collins solution.

monary vascular resistance $\left(1 \pm 0.2 \mathrm{~mm} \mathrm{Hg} \cdot \mathrm{mL}^{-1}\right.$. $\min ^{-1}, P<.05$ versus all other groups), an important hallmark of well-preserved pulmonary grafts (Fig 3).

Experiments next investigated the proinflammatory and cytokine milieu as a potential surrogate marker and likely mediator of graft injury. Because neutrophils that accumulate in the transplanted graft microvasculature can contribute to flow limitations as well as to inflammatory up-regulation and tissue injury, the accumulation of neutrophils was measured by myeloperoxidase assay. Myeloperoxidase, a neutrophil-specific enzyme that transforms hydrogen peroxide into highly toxic oxygen metabolites, can be measured with a chromogenic assay that enables neutrophil accumulation to be quantified. These experiments demonstrated a reduction in graft leukostasis of approximately $44 \%$ in the Columbia University solution group with respect to the other groups (Fig 4), which is not surprising because both nitrovasodilators and cAMP analogs reduce endothelial adhesive properties for leukocytes. Because stimulation of the cAMP second-messenger pathway also reduces TNF- $\alpha$ release by endothelial cells, TNF- $\alpha$ levels were measured in recipient plasma. As predicted, Columbia University solution, which 

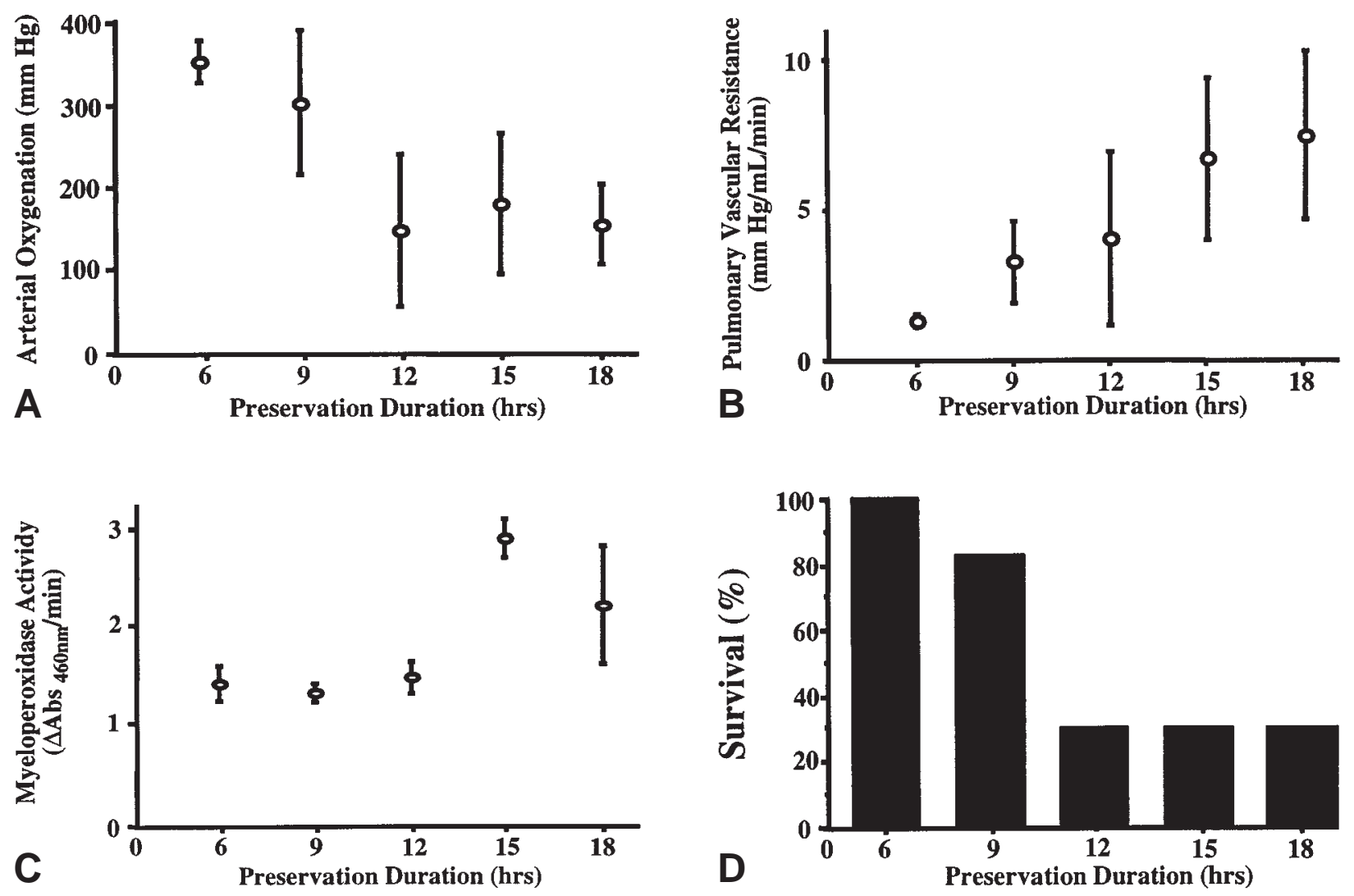

Fig 8. A, Effect of preservation time on arterial oxygenation after lung transplantation. Grafts were preserved in Columbia University solution at $4^{\circ} \mathrm{C}$ for indicated durations, after which they were transplanted orthotopically into strain-matched recipients. At 30 minutes after ligation of native right pulmonary artery or at recipient death, $200 \mu \mathrm{L}$ blood was sampled from left ventricle for blood gas analysis. $\mathrm{N}=8, \mathrm{~N}=8, \mathrm{~N}=3, \mathrm{~N}=3$, and $\mathrm{N}=6$ transplants for preservation durations of $6,9,12,15$, and 18 hours, respectively. B, Effect of preservation time on PVR after lung transplantation. Grafts were preserved in Columbia University solution at $4^{\circ} \mathrm{C}$ for indicated durations, after which they were transplanted orthotopically into strain-matched recipients. At 30 minutes after ligation of native right pulmonary artery or at recipient death, PVR was measured as described in legend to Fig $3 . \mathrm{N}=8, \mathrm{~N}$ $=8, \mathrm{~N}=3, \mathrm{~N}=3$, and $\mathrm{N}=6$ transplants for preservation durations of $6,9,12,15$, and 18 hours, respectively. $\mathbf{C}$, Effect of preservation time on graft neutrophil accumulation after lung transplantation. Grafts were preserved in Columbia University solution at $4^{\circ} \mathrm{C}$ for indicated durations, after which they were transplanted orthotopically into strain-matched recipients. At 30 minutes after ligation of native right pulmonary artery or at recipient death, lung tissue was obtained and myeloperoxidase activity was measured as described in the legend to Fig 4. $\mathrm{N}=8$, $\mathrm{N}=8, \mathrm{~N}=3, \mathrm{~N}=3$, and $\mathrm{N}=6$ transplants for preservation durations of $6,9,12,15$, and 18 hours, respectively. D, Effect of preservation time on recipient survival after lung transplantation. Grafts were preserved in Columbia University solution at $4^{\circ} \mathrm{C}$ for indicated durations, after which they were transplanted orthotopically into strainmatched recipients. Immediately after transplantation native (right) pulmonary artery was ligated, and time until recipient death was recorded. Survivals at 30 minutes are shown. $\mathrm{N}=8, \mathrm{~N}=8, \mathrm{~N}=3, \mathrm{~N}=3$, and $\mathrm{N}=6$ transplants for preservation durations of $6,9,12,15$, and 18 hours, respectively.

contains the cAMP analog db-cAMP, markedly attenuated recipient plasma TNF- $\alpha$ levels compared with those seen in recipients of lungs preserved in EuroCollins solution or University of Wisconsin solution (Fig 5). An unexpected finding was that TNF- $\alpha$ levels were also low in recipients of grafts preserved in lowpotassium dextran glucose solution. We recently showed that IL- $1 \alpha$ synthesized and released directly from ischemic cardiac grafts is an important mechanism in the autoamplification of local leukocyte recruitment and inflammation, ${ }^{37}$ so we measured IL$1 \alpha$ levels to determine whether preservation with Columbia University solution might exert some of its beneficial effects by lowering IL-1 $\alpha$ levels. Among all 
groups studied, local IL- $1 \alpha$ levels were lowest in recipients of grafts preserved with Columbia University solution (Fig 6).

This in vivo lung transplantation model provides the opportunity to use recipient survival as an objective means of summing up the multiple effects of the preservation solutions on the various surrogate end points that we have measured in vitro (harvest vascular resistance, hemodynamic and functional characteristics of the graft, and cytokine levels) in addition to other, unmeasured factors. These data, in which survival time after exclusion of the nontransplanted lung from the pulmonary circulation was recorded for the pre-determined 30-minute period, demonstrated that preserving lungs with Columbia University solution permitted optimal recipient survival compared with the other tested groups (Fig 7). To push the threshold of ischemic injury in this model to test the ability of Columbia University solution to preserve grafts, experiments were performed in which the period of hypothermic preservation was extended for as long as 18 hours (groups of experiments were performed in 3-hour increments of hypothermic ischemia). These experiments demonstrated that Columbia University solution maintained its excellent preservative properties when preservation duration was extended to 9 hours; however, lung graft preservation was poor in this model for periods of 12 hours or longer, even with Columbia University solution (Fig 8, $A$ through $D$ ).

\section{Discussion}

During the processes of harvesting and then transplanting a lung, all cells within the graft are subjected to an obligate period of ischemia followed by reperfusion. Because of the rich vascularity of the lung, maintenance of homeostasis in the pulmonary endothelial cells (which comprise nearly $30 \%$ of the pulmonary parenchymal mass) ${ }^{24}$ is especially critical for successful lung preservation. Two cyclic nucleotides, cGMP and cAMP, are critical intermediaries in multiple aspects of vascular homeostasis; both prevent leukocyte adhesion to endothelium, maintain endothelial barrier properties, are potent vasodilators, and can inhibit platelet reactivity and thrombosis. Both cAMP levels ${ }^{9}$ and nitric oxide (and consequently cGMP) levels ${ }^{5}$ decline markedly during pulmonary reperfusion, so it is surprising that no lung preservation strategy currently in clinical use attempts to buttress either of these pathways.

In this work we hypothesized that supplementing deficient cAMP and nitric oxide-cGMP second-messenger systems by adding a membrane-permeable cAMP ana$\log$ and nitroglycerin to a preservation solution of our own design (Columbia University solution) might improve lung preservation for transplantation. To test this hypothesis these experiments were designed to compare the effects of established lung preservation solutions and Columbia University solution with respect to a number of salient vascular properties, functional characteristics, and cytokine profiles of lung grafts and lung transplantation recipients. These results unequivocally show that Columbia University solution is a superior preservative in the isogeneic orthotopic rat lung transplantation model. When compared with EuroCollins solution, low-potassium dextran glucose solution, and University of Wisconsin solution, only Columbia University solution consistently inhibited the accumulation of neutrophils, reduced recipient levels of proinflammatory cytokines, improved lung graft function, and was associated with high recipient survival.

These studies are especially important in light of the fact that $77 \%$ of all lung transplantation centers worldwide use Euro-Collins preservation solution and 14\% use University of Wisconsin solution (although none use low-potassium dextran for flush perfusion, 1 center flushes grafts with Euro-Collins solution and stores them in low-potassium dextran solution). ${ }^{25}$ Although Columbia University solution has ingredients other than those that preserve endothelial properties, deletion experiments performed when testing Columbia University solution in a rat cardiac transplantation model suggested that nitroglycerin and the cAMP analog were among the 2 most critical ingredients. ${ }^{10}$ These findings are supported by these experiments, in which a version of Columbia University solution was prepared that was devoid of db-cAMP and nitroglycerin; this deleted solution was a poor pulmonary preservative.

Previous mechanistic studies in the same lung transplantation model have been instructional in terms of defining mechanisms whereby nitroglycerin and dbcAMP act to enhance lung preservation. In addition to being potent pulmonary vasodilators, these agents both reduce graft platelet accumulation, edema, and leukostasis. ${ }^{8,9}$ There are multiple mechanisms through which stimulation of the cAMP pathway may inhibit leukocyte accumulation ${ }^{26}$; elevating intracellular cAMP inhibits mobilization and expression of the $\beta_{2}$ integrin $\mathrm{CD} 11 \mathrm{~b} / \mathrm{CD} 18$ on the neutrophil surface, as well as shape change of the neutrophil. ${ }^{27}$ It is possible that qualitative changes or reduced expression of CD11b/CD18 may underlie the antiadhesive actions of cAMP for neutrophils. Nitric oxide donors also have been studied in depth with respect to their ability to inhibit leukocyte adhesion. Although multiple mechanisms may be involved, a mechanism of particular relevance for lung transplantation is the quenching effect of nitric oxide for superoxide, which is a potent neutrophil chemoattrac- 
$\operatorname{tant}^{28}$ that is generated in abundance in the lung reperfusion milieu. ${ }^{5}$ Furthermore, nitric oxide donors appear to reduce expression of P-selectin at the reoxygenated endothelial surface. ${ }^{29,30}$ This latter property may be of especial relevance to lung transplantation, because lung preservation induces P-selectin-mediated leukocyte sequestration that thereby injures the pulmonary graft shortly after reperfusion. ${ }^{6}$

It is interesting to note that in these experiments, Columbia University solution did not exhibit the properties of a harvest vasodilator, which may reflect a combination of the high-potassium base solution (which can vasoconstrict) and the high viscosity of the hypothermic solution caused by the dextran. Nevertheless, previous work has shown that harvest vasodilation by itself is insufficient to preserve lungs, because such potent harvest vasodilators as hydralazine and minoxidil fail to protect the lungs when given during the initial pulmonary flush as a prelude to hypothermic storage. ${ }^{8,9}$

The rationale behind the use of a cell-permeable cAMP analog stems from in vitro observations with cultured endothelial cells exposed to hypoxia and reoxygenation as an in vitro paradigm for the ischemia and reperfusion of transplantation. Endothelial cells exposed to hypoxia exhibit a decline in intracellular levels of cAMP, ${ }^{14}$ with attendant changes in the actinbased cytoskeleton and loss of monolayer properties as a relatively impermeable barrier. Addition of membrane-permeable cAMP analogs that are not subject to hydrolysis, such as db-cAMP, can drive the endothelial phenotype toward normal under conditions of hypoxia $^{14}$ or when ambient levels of TNF- $\alpha$ are elevated. ${ }^{31}$ Although intracellular cAMP can be increased in a number of alternative ways, such as by inhibiting its catabolism with specific cAMP-phosphodiesterases, addition of db-cAMP to a preservation solution seems to be a particularly effective strategy for improving lung preservation. In addition, in vitro studies have shown cAMP analogs such as db-cAMP or 8-bromocAMP to inhibit the LPS-mediated induction of the proinflammatory cytokines TNF- $\alpha$ and interleukin$1 \beta^{32,33}$ and to maintain endothelial anticoagulant properties by preventing the hypoxia-mediated suppression of thrombomodulin. ${ }^{31}$ It has also been reported that $\mathrm{db}-$ cAMP blocks the accumulation of TNF- $\alpha$ transcripts, although in these studies it did not affect the expression of IL-1 $\alpha .34,35$ These in vitro data provide insights into how Columbia University solution may have reduced levels of the proinflammatory cytokines IL- $1 \alpha$ and TNF- $\alpha$ in the lung graft recipients.

Nitric oxide, produced in abundance by the lungs, also has an important role in maintaining vascular homeostatic properties, preventing neutrophil adher- ence to the endothelium, ${ }^{20}$ maintaining endothelial barrier properties, ${ }^{19}$ inhibiting platelet aggregation, ${ }^{4,21}$ and modulating pulmonary vasomotor tone. ${ }^{36}$ Because nitric oxide levels fall abruptly at the onset of reperfusion (as a result of quenching by superoxide), ${ }^{5}$ we hypothesized that the addition of a nitric oxide donor nitroglycerin to the pulmonary preservation solution might help to preserve vascular homeostasis. In previous work we demonstrated that nitroglycerin improves lung preservation in a dose-dependent fashion by improving blood flow, reducing leukocyte and platelet accumulation, and improving gas exchange in the lung transplantation recipient. ${ }^{8}$

On the basis of these considerations of Columbia University solution's ability to maintain endothelial homeostasis by virtue of 2 ingredients added specifically for this purpose, it is not surprising that lungs preserved in it and the recipients of Columbia University solution-preserved grafts fared better in virtually every respect than did their counterparts treated with the other preservation solutions. These studies do not negate an important role for other considerations of preservation solution composition, such as colloids, antioxidants, electrolytes, or impermeant anions. In fact, multiple previous important studies have led to the characterization of many of these additives as critical for a successful preservation solution. Building on this base of knowledge we designed Columbia University solution to go a step further, focusing on 2 additives that improve endothelial function.

The studies presented here demonstrate that lung preservation with Columbia University solution results in optimal graft hemodynamic and functional characteristics, as well as reduced neutrophil infiltration and cytokine levels. Columbia University solution, which contains agents that preserve vascular homeostasis, is superior to other clinically used lung preservation solutions in the rat orthotopic lung transplantation model. These studies show that Columbia University solution warrants testing in larger animals and possibly even in humans.

\section{REFERENCES}

1. Hosenpud JD, Bennett LE, Keck BM, Fiol B, Novick RJ. The registry of the international society for heart and lung transplantation: fourteenth official report-1997. J Heart Lung Transplant 1997; 16:691-712.

2. Christie JD, Bavaria JE, Palevsky HI, Litzky L, Blumenthal NP, Kaiser LR, et al. Primary lung graft failure following lung transplantation. Chest 1998;114:51-60.

3. Pinsky D, Oz M, Liao H, Morris S, Brett J, Sciacca R, et al. Restoration of the cAMP second messenger pathway enhances cardiac preservation for transplantation in a heterotopic rat model. J Clin Invest 1993;92:2994-3002. 
4. Pinsky DJ, Oz MC, Koga S, Taha Z, Broekman MJ, Marcus AJ, et al. Cardiac preservation is enhanced in a heterotopic rat transplant model by supplementing the nitric oxide pathway. J Clin Invest 1994;93:2291-7.

5. Pinsky DJ, Naka Y, Chowdhury NC, Liao H, Oz MC, Michler $\mathrm{RE}$, et al. The nitric oxide/cyclic GMP pathway in organ transplantation: critical role in successful lung preservation. Proc Natl Acad Sci U S A 1994;91:12086-90.

6. Naka Y, Toda K, Kayano K, Oz MC, Pinsky DJ. Failure to express the P-selectin gene or P-selectin blockade confer early pulmonary protection after lung ischemia or transplantation. Proc Natl Acad Sci U S A 1997;94:757-61.

7. Pinsky DJ, Naka Y, Liao H, Oz MC, Wagner DD, Mayadas TN, et al. Hypoxia-induced exocytosis of endothelial cell WeibelPalade bodies: a mechanism for rapid neutrophil recruitment after cardiac preservation. J Clin Invest 1996;97:493-500.

8. Naka Y, Chowdhury NC, Liao H, Roy DK, Oz MC, Michler RE, et al. Enhanced preservation of orthotopically transplanted rat lungs by nitroglycerin but not hydralazine: requirement for graft vascular homeostasis beyond harvest vasodilation. Circ Res 1995;76:900-6

9. Naka Y, Roy DK, Liao H, Chowdhury NC, Michler RE, Oz MC, et al. cAMP-mediated vascular protection in an orthotopic rat lung transplant model: insights into the mechanism of action of prostaglandin E1 to improve lung preservation. Circ Res 1996; 79:773-83.

10. Oz MC, Pinsky DJ, Koga S, Liao H, Marboe CC, Han D, et al. Novel preservation solution permits 24-hour preservation in rat and baboon cardiac transplant models. Circulation 1993;88(Pt 2): 291-7.

11. Ogawa S, Gerlach H, Esposito C, Pasagian-Macaulay A, Brett J, Stern D. Hypoxia modulates the barrier and coagulant function of cultured bovine endothelium. Increased monolayer permeability and induction of procoagulant properties. J Clin Invest 1990; 85:1090-8.

12. Shreeniwas R, Koga S, Karakurum M, Pinsky D, Kaiser E, Brett $\mathrm{J}$, et al. Hypoxia-mediated induction of endothelial cell interleukin-1 alpha: an autocrine mechanism promoting expression of leukocyte adhesion molecules on the vessel surface. J Clin Invest 1992;90:2333-9.

13. Yoshida N, Granger DN, Anderson DC, Rothlein R, Lane C, Kvietys PR. Anoxia/reoxygenation-induced neutrophil adherence to cultured endothelial cells. Am J Physiol 1992;262: H1891-8.

14. Ogawa S, Koga S, Kuwabara K, Brett J, Morrow B, Morris SA, et al. Hypoxia-induced increased permeability of endothelial monolayers occurs through lowering of cellular cAMP levels. Am J Physiol 1992;262:C546-54

15. Stelzner TJ, Weil JV, O'Brien RF. Role of cyclic adenosine monophosphate in the induction of endothelial barrier properties. J Cell Physiol 1989;139:157-66.

16. Boxer LA, Allen JM, Baehner RL. Diminished polymorphonuclear leukocyte adherence: function dependent on release of cyclic AMP by endothelial cells after stimulation of beta-receptors by epinephrine. J Clin Invest 1980;66:268-74.

17. Pober JS, Slowik MR, De Luca LG, Ritchie AJ. Elevated cAMP inhibits endothelial synthesis and expression of ELAM-1 and VCAM-1, but not ICAM-1. J Immunol 1993;150:5114-23.

18. Haynes J Jr, Robinson J, Saunders L, Taylor AE, Strada SJ. Role of cAMP-dependent protein kinase in cAMP-mediated vasodilation. Am J Physiol 1992;262:H511-6.
19. Kubes P, Granger DN. Nitric oxide modulates microvascular permeability. Am J Physiol 1992;262:H611-5.

20. Kubes P, Suzuki M, Granger DN. Nitric oxide: an endogenous modulator of leukocyte adhesion. Proc Natl Acad Sci U S A 1991;88:4651-5

21. Radomski MW, Palmer RM, Moncada S. Endogenous nitric oxide inhibits human platelet adhesion to vascular endothelium. Lancet 1987;2:1057-8.

22. Keshavjee SH, Yamazaki F, Yokomise H, et al. The role of dextran 40 and potassium in extended hypothermic lung preservation for transplantation. J Thorac Cardiovasc Surg 1992;103:314-25.

23. Chowdhury NC, Naka Y, Pinsky DJ, et al. Novel technique of orthotopic lung transplantation in rats in which survival and hemodynamic assessment can be measured independent of the native lung. Surg Forum 1994;45:268-70.

24. Crapo JD, Barry BE, Gehr P, Bachofen M, Weibel ER. Cell number and cell characteristics of the normal human lung. Am Rev Respir Dis 1982;125:740-5.

25. Hopkinson DN, Bhabra MS, Hooper TL. Pulmonary graft preservation: a worldwide survey of current clinical practice. J Heart Lung Transplant 1998;17:525-31.

26. Bryant RE, Sutcliffe MC. The effect of 3',5'-adenosine monophosphate on granulocyte adhesion. J Clin Invest 1974; 54:1241-4.

27. Derian CK, Santulli RJ, Rao RE, Solomon HF, Barrett JA. Inhibition of chemotactic peptide-induced neutrophil adhesion to vascular endothelium by cAMP modulators. J Immunol 1995; 154:308-17.

28. Kubes P, Kanwar S, Niu XF, Gaboury JP. Nitric oxide synthesis inhibition induces leukocyte adhesion via superoxide and mast cells. FASEB J 1993;13:1293-9.

29. Liao H, Heath M, Pinsky DJ. Stimulation of the NO/cGMP pathway reduces hypoxia-induced endothelial P-selectin expression a mechanism whereby nitrosovasodilators reduces neutrophil adhesion (abstract). Circulation 1996;94:I634.

30. Armstead VE, Minchenko AG, Schuhl RA, Hayward R, Nossuli TO, Lefer AM. Regulation of P-selectin expression in human endothelial cells by nitric oxide. Am J Physiol 1997;273:H740-6.

31. Koga S, Morris S, Ogawa S, Liao H, Bilezikian JP, Chen G, et al. TNF modulates endothelial properties by decreasing cAMP. Am J Physiol 1995;268:C1104-13.

32. Hoek J. Intracellular signal transduction and the control of endothelial permeability. Lab Invest 1998;67:1-4

33. Yoshimura T, Kurita C, Nagao T, Usami E, Nakao T, Watanabe S, et al. Inhibition of tumor necrosis factor-alpha and interleukin-1beta production by beta-adrenoceptor agonists from lipopolysaccharide-stimulated human peripheral blood mononuclear cells. Pharmacology 1997;54:144-52.

34. Zhong WW, Burke PA, Drotar ME, Chavali SR, Forse RA. Effects of prostaglandin E2 cholera toxin and 8-bromo-cyclic AMP on lipopolysaccharide-induced gene expression of cytokines in human macrophages. Immunology 1995;84:446-52.

35. Righi M. Modulation of cytokine expression by cAMP analogs in myc-immortalized microglial cell lines. Funct Neurol 1993;8: 359-63.

36. Lawson CA, Smerling AJ, Naka Y, Burkhoff D, Dickstein ML, Stern DM, et al. Selective reduction of PVR by inhalation of a cGMP analogue in a porcine model of pulmonary hypertension. Am J Physiol 1995;268:H2056-62.

37. Wang K, Naka Y, Oz MC, Gutierrez-Ramos J-C, Springer TA, Pinsky DJ. Cardiac graft ICAM-1 and IL-1 expression mediate primary isograft failure and induction of ICAM-1 in organs remote from the site of transplantation. Circ Res 1998;82:762-72. 